\title{
THE IMPACT OF
}

\section{ACADEMIC RESEARCH IN FINANCE}

\author{
(IMPACT RATIO)
}

\section{Submission journal: Research in Finance}

\begin{abstract}
Academic institutions are under increasing pressure to show that their research output has impact. As this concept is easier to quantify in science based disciplines, this paper reviews how one interprets what impact is in finance. It suggests how best to incorporate it into academic research through the use of a simple to understand Impact Ratio. It provides an overview of the leading academic publications and their role in this process. It asks how impact within finance is understood, appreciated, and subject to critique. It concludes that academics should demonstrate how they can facilitate the development of capital markets through evidence based policy and enhancing capital market efficiency.
\end{abstract}

Keywords: Impact, Finance, capital markets, market efficiency, research, information, public policy, and knowledge economy.

\section{JEL Classification: G00}

\section{INTRODUCTION}

Academic institutions not only teach the body of knowledge in finance but develop it further through research. It is has long been accepted that this, through peer reviewed theoretical research, drives both growth and innovation. More effective capital markets and capital decisions is pareto optimal for society. Indeed, academic impact is defined as "the demonstrable contribution that excellent research makes to society and the economy". ${ }^{1}$ That said, within finance, academics are often left outpaced by the speed of innovation in financial markets. Their impact is not as visible as that of initiatives by investment banks or other financial institutions. This paper therefore takes an unconventional approach and reviews the impact of theoretical research in finance. In this way, it is hoped it will assist academics make more informed research choices and outcomes. It will also help them focus more on what impact means.

\footnotetext{
${ }^{1}$ Research Councils UK (RCUK)
} 
As readers of the Research In Finance know, academic finance research involves making hypothesis, quantitative testing, and creating models. Applied finance is the application of these. Each element has a greater or lesser emphasis. That said, creating theoretical models will always be the goal for cutting edge research. As such, it can be argued that model generation should not form part of the impact debate. Once such models exist, impact can be accessed.

Essentially, the focus on academic impact should not be about predicting outcomes but about quantifying potential benefits. This often means making an impact on policy. Practical finance outpaces the speed of peer reviewed rigor. Academics and policy makers both require reasoned thought and process in order to make conclusions.

Impact can sound very abstract. A fair criticism of this paper, for example, would be that it does not have impact. This criticism is common of many papers. It highlights the difference between relevance and impact. Hopefully this paper, like others in finance, has relevance to the reader even if it does not have impact. It should be emphasized that impact in finance is viewed differently from other sciences. Typical impacts areas in other academic disciplines can include education, quality of life, public knowledge, professional practice, law, sustainability and creativity. These are harder to quantify.

Frequently used impact techniques include, life cycle assessment, cost-benefit analysis, return on investment, multi-criteria assessment, risk assessment and total economic impact auditing. The latter is done empirically by calculating the sum of its direct, indirect and induced impacts. There is also a great deal of focus on societal impacts, as mentioned. In this respect, finance research tends to justify itself on the efficiency it brings to the process of allocating scarce economic resources rather than softer factors. The role played by finance research includes improving risk management (Froot, Scharfstein and Stein 1993), curbing agency problems (Jensen and Meckling 1976) and alleviating informational asymmetries (Myers and Majluf 1984).

Whilst promoting impact sounds like a positive thing to do, one still has to ask the introspective question of whether intellectual integrity can be eroded in its pursuit. The various research councils that are promoting it want to ensure that research makes a difference. This creates a danger that bias may creep in to the process. Academics could end up seeking results that are desired for impact. To avoid this, questions should be asked. For example, to what extent does impact have to rely on academic literature? Also, how different types of research differ in their impact. In this way, academics can remain impartial, the key to critical reasoning.

\section{EXAMPLES OF IMPACT}

There are many strands of finance research, some more impactful than others. For the sake of the model introduced latter, the key areas are broken down into the following segments, namely capital decisions, capital structure, capital markets and capital pricing. 
- Research into capital decisions focuses on firm structure and the amount of leverage a firm should optimally have. This impacts capital investment decisions. (Myers and Majluf 1984) is the most cited research in this field. They developed a model to help understand how new capital can be used to fund profitable projects. In this strand of research, it is generally agreed that leverage increases with fixed assets, tax shields, growth opportunities, and/or firm size. The research focus into capital decisions has largely been to identify such factors and account for them. The conclusions from such research largely involve specific predictions about the signs of the coefficients that should be observed.

- Research into capital structure focuses on governance and internal corporate capital allocation. This impacts capital structure decisions. The seminal work of (Modigliani and Miller 1958) on the cost of capital springs to mind. More recently, articles on investor protection and corporate governance have scored particularly well in citation rankings. Financial intermediation and liberalization are also hot topics. Policy makers are focusing on this topic, particularly in respect of pay and incentives. The role of institutional investors is under scrutiny, so research designed to improve institutional investor involvement and shareholder participation will certainly have impact. The billions of dollars of fines paid by the banks are testimony to the importance of getting governance right.

- Research into capital markets is focused on market efficiency. The impact of research on efficiency can be seen in capital markets transactions. The foundation of much of this genre is Modern Portfolio Theory. This line of research was certainly impactful when the implications of competitive equilibrium were first expanded on by (Sharpe, Capital asset prices: A Theory of Market Equilibrium Under Conditions of risk. 1964), (Lintner 1965) and (Mossin 1966). Similarly, (Black and Scholes 1973) pricing of options had a transformative effect on the finance industry.

- Research into capital pricing focuses on asset pricing theory. The impact of this research is in improvement in the pricing of securities Impactful extension of the CAPM, such as including the effects of taxation (M. J. Brennan 1970) and adjusting for riskless assets (F. Black 1972) were helpful in translating theory into practical application. Real world adaptions, such as (Merton 1973) inter-temporal capital asset pricing model which allowed for continuously traded assets to be incorporated. This made the theory more practical. Such innovations helped move away from the simple assumptions of the earlier models but could not be said to be impactful. The impact of the further refinements, the consumption asset based pricing models aside, were limited because practitioners could not or would not apply them.

\section{IMPROVING EFFICIENCY}

Improving market efficiency is an important component of impact because it is the backbone of finance. It provides the basis for price discovery and the continuous restructuring of the economy. It supports economic growth and facilitates capitalism. On a similar note, sound implementation of financial theory improves the efficiency of capital decisions, thereby 
favoring a better allocation of scarce economic resources. Research that improves the efficiency of this process therefore has real impact across the whole of society.

Improvements in efficiency can be quantified, measured and monitored. Market efficiency and capital asset pricing are key areas where empirically testable impact can be made. Indeed, the testing of asset pricing models, anomalies and portfolio strategies has become a big part of finance research. Such work builds on the relationship between risk and return and is the bedrock of practical asset management. That said, this area of research often pits academia against the world of active asset managers. ${ }^{2}$ Academics tend to be too dismissive of the persistence of Jensens Alpha (Risk adjusted investment outperformance). It is a grey zone that impact needs to be more clearly delineated.

The extensive sempirical testing into the persistence of alpha moved academia away from impactful research. Robustness tests have become the norm, based on a concern that the quality of individual academics finance research could be perceived as uneven and/or lacking in credibility. It has, as a result, become difficult for finance academics to make confident, concrete assertions or predictions.

Despite these concerns about academic research, one has to give credit where credit is due. The most impactful asset pricing research has led to industry innovation and shaped the capital markets into what they are today.

A large part of the world's professionally managed money is now passively indexed. That is almost exclusively an academic impact. It doesn't end there. The Arbitrage Pricing Theory spawned a factor based risk evaluation and optimization industry. The Black Scholes options pricing model kick-started the dramatic growth in the financial derivatives markets. The characteristics that (Fama and French 1993) showed to have some predictive ability led to style based investing.

Within the field of benchmarks, the Jensen measure of portfolio performance (Jensen 1968) and the Sharpe ratio, that maximizes the ratio of expected return to the standard deviation of a portfolio are clear examples of impactful research (Sharpe, Capital asset prices: A Theory of Market Equilibrium Under Conditions of risk. 1964).

The list goes on. That said, many leading papers have not had this sort of industry wide impact. (Ferson and Harvey 1991), to name but one example, estimated and tested the conditional version of the ICAPM allowing for time variation of beta. They produced an important and much cited paper. Their work facilitated accurate measurement of the performance of actively managed funds. The finance industry did not adopt their work. This focus on quality rather than impact is repeated in many heavily cited papers as well as much of the less cited ones, top academics as well as junior ones.

Much of the inertia to academic research can be put down to practitioner's complaints about the assumption academics make and on which finance models are built. They argue that

\footnotetext{
${ }^{2}$ Because the CAPM, ICAPM and the equilibrium version of the APT all imply that alpha should be zero.
} 
individuals are not rational, markets are not frictionless, information is not ubiquitous and data normally distributed. They have a point. The theoretic research done by academics in finance has a habit of ignoring asymmetric information, trading costs, Illiquidity and taxation (to name but a few).

The drive towards more impact could well move some research into more relevant practical investigation of these issues. There are many precedents. (Amihud and Mendelson 1986), for example, incorporated the bid ask spread into the cost of trading. (Brennan and Subrahmanyam 1996) included a measurement of illiquidity in their work on intraday trading. As data becomes cheaper, more frequent and more abundant to access, such impactful research will no doubt increase.

Perhaps the most pertinent way to illustrate the impact of academic research is to look at an academic who has monetized his work. Rob Arnott, the former editor of Financial Analysts Journal, is a case in point. He had published more than 100 peer reviewed papers prior to establishing an asset management company ${ }^{3}$. He built this company into a multi billion dollar asset manager on the back of research he had published on the performance metrics of market indexes weighted by fundamental metrics. His work essentially gave rise to a whole industry called "fundamental indexation" (Arnott, Hsu and Moore 2005). That is impact.

\section{RESEARCH OUTPUT}

As is hopefully clear by now, impact is not the same thing as research output. At present, published research papers are typically used to assess the performance of finance faculty. This process is institutionalised through the Journal rating system and has become central to university life. The rating system is as follows:

- Four star: Quality that is world-leading in terms of originality, significance and rigor.

- Three star: Quality that is internationally excellent in terms of originality, significance and rigor but which falls short of the highest standards of excellence.

- Two star: Quality that is recognized internationally in terms of originality, significance and rigor.

- One star: Quality that is recognized nationally in terms of originality, significance and rigor.

- Unclassified Quality: that falls below the standard of nationally recognized work. Or work which does not meet the published definition of research for the purposes of this assessment.

Using this methodology, the leading four star finance publications are widely considered to be Financial Management, Journal of Business, Journal of Finance, Journal of Financial and Quantitative Analysis, Journal of Financial Economics, and Review of Financial Studies.

\footnotetext{
${ }^{3}$ Research Affiliates.
} 
Pre-eminent amongst these is the Journal of Finance. That said, all have a focus on statistical rigour. A good pecking order of finance publications is produced by (Zivney and Reichenstein 1994). The Financial Analysts Journal is seen as the pre-eminent of the practitioner journals.

Increasingly, top-level finance research is interdisciplinary with many papers in finance also being published in the four star publications of other disciplines such as Econometrica, Journal of Accounting and Economics, Journal of Political Economy, Quarterly Journal of Economics, and American Economic Review. ${ }^{4}$ Leading financial newspapers like the Financial Times and the Wall Street journal have great influence when relating financial issues, but this is not the same thing as academic impact.

The academic reward system depends heavily on citations. Rank listings for Universities and business schools include citations in top journals. Indeed, even being part of such a ranking tends to effect where academics publish their papers. For example, there are 45 journals in the Financial Times Business School research rank. These are widely followed in the United Kingdom. The pure finance related journals in this are the same as the leading ones above, with the exception of The Accounting Review, Journal of Accounting Research, Rand Journal of Economics and Review of Accounting Studies. A good review of the finance Journals is provided by (Arnold, et al. 2003).

There have been a few investigations into citations. (Bricker, Borokhovich and Simkins 2003), for example, assesses the impact of papers published in accounting journals using both citation methods and content analysis. In contrast to the widely held view on the influence of finance research on accounting, their results show that academics have relatively little real world impact on accounting.

\footnotetext{
${ }^{4}$ Academics also consider the following journals worthy of publication. European Financial Management, Finance and Stochastics, Financial Management, Financial Review, International Review of Finance, Journal of Applied Corporate Finance, Journal of Banking and Finance, Journal of Business Finance and Accounting, Journal of Corporate Finance, Journal of Empirical Finance, Journal of Financial Intermediation, Journal of Financial Markets, Journal of Financial Research, Journal of Financial Services Research, Journal of Futures Markets, Journal of International Money and Finance, Journal of Multinational Financial Management, Journal of Portfolio Management, Journal of Risk and Insurance, Mathematical Finance, Pacific-Basin Finance Journal, Review of Finance, and Review of Quantitative Finance and Accounting.
} 
Papers in finance journals are usually classified according to the JEL classification codes, a system run by the Journal of Economic Literature and published by the American Economic Association. The top five research financial economics subcategories are:

G120 Asset pricing; trading volume; bond interest rates

G320 Financing policy; financial risk and risk management; capital and ownership structure

G110 Portfolio choice; investment decisions

G140 Information and market efficiency; event studies

G210 Banks; other depository institutions; micro finance institutions; mortgages

The output is quite impressive. There are some 1,400 recognized social sciences journals accepting these classifications. The Social Sciences Citation Index reports in the Journal Citation Record how many citations each of these get. In addition to this measure, there is also a widely quoted commercial journal impact factor. This is proprietary and produced by Thomson Reuters. Both of these measure impact purely in relation to citations.

Citations are very relevant to academics although clearly less so practitioners. Publications in influential finance journals are significant career milestones for them. It is not surprising that (Swidler and Elizabeth 1998) find that papers published in the most influential finance journals affect the salaries of finance faculty. In a similar vein (Fishe 1998) showed that full professors in finance from the top twenty faculties published an average of 1 out of 3 articles in either Journal of Finance, Review of Financial Studies, or Journal of Financial Economics compared to 1 out of 6 articles for professors at other universities.

\section{RESEARCH QUALITY}

It is fair to say that the quality of research does vary, hence the journal rating system. It is not surprising that (Boaz and Ashby 2003) found that the design, questions, methods, coherence, and consistency of findings influence the type and quality of research produced. The unifying concepts of regression and correlation underlie many of the sophisticated models and techniques in financial research. Quality research typically includes such methods.

As has been noted, publication in top research journals is perceived to be the greatest indicator of research quality. This does not, however, say very much about what it takes to define quality (Smith 2004). Research built on rigorous peer review and an existing body of literature may well have the hallmarks of quality but have little relevance and impact.

Essentially, good research should include a clear statement of research aims. These should define the research question. The subsequent methodology should be appropriate to this. The research can be either qualitative or quantitative but there is clearly a bias in finance to the latter. More than one combination of methodologies and statistical analysis helps the robustness of the conclusions. Quality research should also be unbiased. 


\section{MEASURING IMPACT}

Finance is a quantitative discipline. As such, researchers should try and measure the impact of their work as much as possible. It should be measured because impact is an increasingly important item to secure funding. Demonstrating impact can also bring academics closer to the practitioners, thereby improving the output of research.

Academics tend to not understand the concept of impact and what it brings to the table. (Brinn, Jones and Pendlebury 2001) surveyed finance researchers and found that they believed the current impact push had a negative rather than a positive effect upon their jobs. The finding was fairly homogeneous across universities. However, the responses of senior and non-senior staff were significantly different.

Impact measurement is a form of performance monitoring. Embedding the concept of impact measurement within a finance department gives a visible external metric for judging success and demonstrating the research is delivering to its beneficiaries. The process should be integral to the research and the following five steps are recommended to begin the evaluation.

- Identification of a research project's possible impacts and their separation from those that are not significant.

- Rationale of the purpose of the research and an understanding of its various characteristics within the context of existing finance theory.

- Prediction of any identified change in the market microstructure, modus operani of companies, or capital market efficiency.

- Evaluation of the relative significance of the predicted impacts (see Impact Ratio below).

- Public consultation and participation aim to ensure the quality, comprehensiveness and effectiveness in any decision-making process.

There are many ways to do this including contingencies, consumer surpluses, net economic value or return on investment. Any of these can be adapted. This paper however proposes the following quantitative way for a researcher try to measure impact. Think of it as a ratio of the return on the time and cost involved. The Impact Ratio for research that enhanced market efficiency would look like:

$$
I R=\sum_{T=1}^{N} \frac{E c d+E c s+E c m+E c p}{\left(R+G+P^{t+1}\right)}
$$


IR = Impact Ratio

Ecd $=$ Efficiency improvement in capital investment decisions (discounted present value)

Ecs $=$ Efficiency improvement in capital structure decisions (discounted present value)

Ecm $=$ Efficiency improvement in capital markets transactions (discounted present value)

$E c p=$ Efficiency improvement in pricing of securities (discounted present value)

$R=$ Indirect costs (eg: time apportionment of salary and overheads)

$G=$ Direct costs (eg: grant/budget spent on data)

$N=$ Until the time at which the particular research output persists

$P^{t+1}=$ Post publication awareness and promotion costs.

The intuitive nature of the Impact Ratio means that one can estimate it and still find it useful. The probability of having an Impact Ratio of close to one or below one would imply a piece of research does not have enough impact to justify its cost. A high Impact ratio, above ten, would suggest that the research be done at a sufficiently rigorous level to get it accepted in a four star journal.

Research that scores poorly on the Impact Ratio is not necessarily poor research. A great deal of maintenance research is required to dynamically build on the existing body of knowledge. Increased sample sizes, updated time series, new or adapted statistical robustness tests, or simply application of existing models to new problems is all legitimate academic enquiry. It just does not have impact.

The Impact Ratio approach has the most flattering outcome because the input costs are typically far lower than the economic benefits of enhanced market efficiency. Any number above one would mean the return on impact was worth the effort.

\section{CONCLUSIONS}

The observations in this paper have important implications, particularly for the recruitment and retention of future finance faculty. It highlights the importance of quantifying the demonstrable contribution that excellent finance research makes to capital markets. The paper therefore proposes an Impact Ratio be used. This will help stakeholders to better understand advances in market efficiency and policy. The advantages of this are that it demonstrates relevance and focus. 
Finance research should be instrumental in influencing the development of policy, shaping legislation, and or altering behavior in order to have more efficient capital markets. In this respect it needs to be both conceptual and able to develop knowledge. It has to maintain its focus on improving the efficiency and free working of capital markets by being relevant. In that way, the impact of finance research will be for the benefit of society as a whole. 


\section{Bibliography}

Amihud, $\mathrm{Y}$, and H. Mendelson. " Asset pricing and the bid-ask spread." ( Journal of financial Economics) 17(2), 223-249. (1986).

Arnold, T., A. W. Butler, F. Timothy, Crack, and Altintig. "“'Impact: What Influences Finance Research?"." ( Journal of Business, ) 76(2), 343-61. (2003).

Arnott, R, J Hsu, and P Moore. "'Fundamental indexation." ." Financial Analysts Journal., 2005: 61, no. 2 83-99.

Black, F, and M Scholes. "'The pricing of options and corporate liabilities."." The journal of political economy, 1973: 637-654.

Black, F. "Capital market equilibrium with restricted borrowing." ( Journal of business) 444-455. (1972).

Boaz, A., and D. Ashby. Fit for purpose? Assessing research quality for evidence based policy and practice. ESRC UK Centre for Evidence Based Policy and Practice, 2003.

Borokhovich, K, R Bricke, and Simkins D. "Journal communication and influence in financial research ." (Journal of Finance ) 49, 713-725. (994).

Brennan, and Subrahmanyam. "'Market microstructure and asset pricing: On the compensation for illiquidity in stock returns." ." (Journal of financial economics ) 41.3 (1996): 441-464. (1996).

Brennan, Michael J. "'Taxes, market valuation and corporate financial policy." ." (National Tax Journal) 417-427. (1970).

Bricker, R., K. Borokhovich, and B. Simkins. "The impact of accounting research on finance. ." (Critical Perspectives on Accounting,) 14(4), 417-438. (2003).

Brinn, T., M. Jones, and M Pendlebury. "The impact of research assessment exercises on UK accounting and finance faculty." (The British Accounting Review ) 33.3: 333-355 (2001).

Fama, E, and K. French. "'Common risk factors in the returns on stocks and bonds."." Journal of financial economics, 1993: 33, no. 1 (1993): 3-56.

Ferson, W, and C. Harvey. "The variation of economic risk premiums.." (Journal of Political Economy ) 385-415 (1991).

Fishe, R. "What are the research standards for full professor of finance? ." (Journal of Finance ) 53, 1053-1079. (1998).

Froot, K, J Scharfstein, and D Stein. "Risk management: Coordinating corporate investment and financing policies." (The Journal of Finance) 48 (5), 1629-1658. (1993). 
Jensen, Michael, and W Meckling. "Theory of the firm: Managerial behavior, agency costs and ownership structure." ( Journal of Financial Economics ) 3 (4), 305-360. (1976).

Lintner, John. "'The valuation of risk assets and the selection of risky investments in stock portfolios and capital budgets."." ( The review of economics and statistics ) 13-37. (1965).

Merton, R. "An intertemporal capital asset pricing model., ." ( Econometrica: Journal of the Econometric Society) 867-887. (1973).

Modigliani, Franco, and Merton Miller. " "The cost of capital, corporation finance and the theory of investment." ." The American economic review (1958): 261-297., 1958: 261-297.

Mossin, Jan. “"Equilibrium in a capital asset market."." (Econometrica) 768-783. (1966).

Myers, S, and N Majluf. " Corporate financing and investment decisions when Firms have information that investors do not have, ." Journal of Financial Economics , 1984: 13, 187-221.

Myers, Stewart, and Nicolas Majluf. "Corporate financing and investment decisions when firms have information that investors do not have." ( Journal of Financial Economics ) 13 (2), 187-221. (1984).

Sharpe, W. "Capital asset prices: A theory of market equilibrium under conditions of risk." The journal of finance, 1964: 19, no. 3 425-442.

Sharpe, W. "Capital asset prices: A Theory of Market Equilibrium Under Conditions of risk." (Journal of finance) 19 (1964).

Smith, S. "'Is an Article in a Top Journal a Top Article?" ." (Financial Management ) 33, (No. 4, Winter), 133-149. (2004).

Swidler, Steve, and Goldreyer Elizabeth. "The value of a finance journal publication ." (Journal of Finance ) 53, 351-363. (1998).

Teece, David J. "'Towards an economic theory of the multiproduct firm." ." (Journal of Economic Behavior \& Organization ) 3.1 : 39-63. (1982).

Zivney, T., and W Reichenstein. "The pecking order in finance journals. ." (Financial Practice and Education ) 4 (Fall-Winter): 77-87. (1994). 